\title{
Cascade and multicomponent synthesis of structurally diverse 2- (pyrazol-3-yl)pyridines and polysubstituted pyrazoles
}

Received 00th January 20xx, Accepted 00th January 20xx DOI: $10.1039 / \times 0 \times x 00000 x$

\begin{abstract}
Raquel Barroso, María-Paz Cabal, Azucena Jiménez, * and Carlos Valdés*a
The cascade reaction between $\mathrm{N}$-tosylhydrazones and 2-alkynylpyridines leads to 2-(pyrazol-3-yl)pyridines, important structural motifs in ligands for transition metals and bioactive molecules. When the reaction is conducted with 2,6diethynylpyridine the important 2,6-bis(pyrazolyl)pyridines are obtained, featuring the arrangement of tridentate and also pentadentate ligands. A novel three-component version of the reaction has been designed, which involves the use of $\alpha$ bromo- $\mathrm{N}$ - tosylhydrazones, alkynylpyridines and $\mathrm{NH}$-azoles. The generality of the multicomponent reaction is further illustrated by the preparation of different polysubstituted pyrazoles employing an array of terminal alkynes. In these multicomponent reactions, complex molecules featuring three different heterocycles are assembled in one single step from commercial materials enabling the fast generation of molecular diversity.
\end{abstract}

\section{Introduction}

The pyrazole heterocycle is a privileged structure of outmost importance in current organic chemistry. ${ }^{1}$ The pyrazole structural motif is present in a wide number of molecules with biological activity with medicinal applications, ${ }^{2}$ and are also very useful structural fragments in supramolecular chemistry, ${ }^{3}$ coordination chemistry, ${ }^{4}$ catalysis ${ }^{5}$ and materials chemistry. ${ }^{6}$ In particular, the 2-(pyrazol-3-yl)pyridine moiety A (Figure 1) represents a very common fragment that is present in a large number of metal complexes with catalytic activity. ${ }^{7}$ Moreover, this bidentate substructure has been also employed as key element in the design of coordination complexes with interesting electronic properties, ${ }^{8}$ as well as fundamental building block for supramolecular coordination complexes that feature a variety of applications. ${ }^{9}$ Furthermore, the 2-(pyrazol3 -yl)pyridine moiety is also present in molecules with reported biological activities and therapeutical applications. ${ }^{10} \mathrm{~A}$ particularly important class of compounds are 2,6bis(pyrazolyl)pyridines (bpp) B (Figure 1). ${ }^{11}$ This family of trisheterocyclic ligands has attracted enormous attention due to their unique metal binding properties. On one side, they have been shown to produce coordination complexes featuring properties such as spin-crossover ${ }^{12}$ or luminescence. ${ }^{13}$ Additionally, 2,6-bis(pyrazolyl)pyridine transition metal complexes are efficient catalysts in a variety of organic transformations. ${ }^{14}$

\footnotetext{
a. Departamento de Química Orgánica e Inorgánica and Instituto Universitario de Química Organometálica "Enrique Moles". Universidad de Oviedo. c/ Julián Clavería 8. Oviedo 33006. Spain.E-mail: azujp@hotmail.com; acvg@uniovi.es Electronic Supplementary Information (ESI) available: [details of any supplementary information available should be included here]. See DOI: 10.1039/x0xx00000x
}
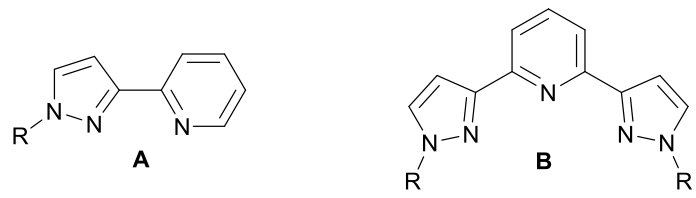

Figure 1. 2-(1H-pyrazol-3-yl) pyridine $\mathbf{A}$ and 2,6-bis-[2-(1H-pyrazol-3-yl)]pyridine B substructures

In spite of the wide interest and applications of the 2-(pyrazol3-yl)pyridine substructure, the methods for the synthesis of polysubstituted systems are quite limited, and usually require stepwise protocols with poor yields, and thus have been applied to a limited number of substituents. Therefore, the ability to synthesize structurally diverse 2-(pyrazol-3-yl)pyridines in an efficient and straightforward manner from easily available materials might be of great interest, as it would enable to study the influence of the substituents in the properties or these important types of molecules both in medicinal chemistry and catalysis.

We have recently reported a novel method for the synthesis of polysubstituted pyrazoles by a 1,3-dipolar cycloaddition/1,5sigmatropic rearrangement sequence starting from $\mathrm{N}$ tosylhydrazones derived from ketones and terminal alkynes (Scheme 1, a). ${ }^{15}$ The method is very general and regioselective, and depending on the structure of the $\mathrm{N}$-tosylhydrazone allows for the selective synthesis of 3,4,5- or 1,3,5-trisubstituted pyrazoles. Moreover, the employment of $\mathrm{N}$-tosylhydrazones derived from ketones featuring a sterogenic center in the $\alpha$ carbon, leads to chiral pyrazoles with the stereogenic center attached at the nitrogen atom (Scheme 1, a). ${ }^{16}$

We envisioned that the employment of a 2-alkynylpyridine in the cascade reaction would lead in a very straightforward manner to 2-(pyrazol-3-yl)pyridines (Scheme 1, b). Considering the modularity and wide scope of the reaction, this general approach might allow to access to an ample variety of 
structures featuring this bidentate ligand moiety, enabling the flexible modification of steric and electronic properties of potential ligands. The implementation of this methodology has allowed us to devise efficient synthetic routes that gain access to a variety of polyheterocyclic systems featuring the 2(pyrazol-3-yl)pyridine moiety, that might be used as bidentate, tridentate and even pentadentate chelating ligands (Scheme 1, c).<smiles>[R]C(=NN)C([R])[X]</smiles><smiles>[R]C(=N)C([R])[X]</smiles>

b)

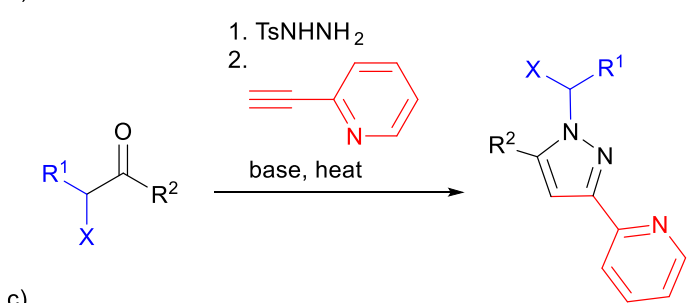

c)

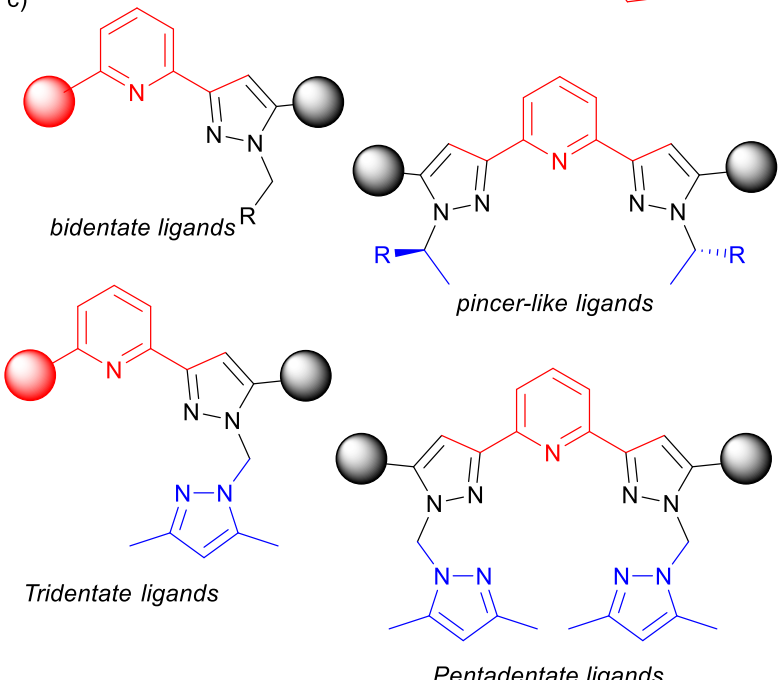

Scheme 1. a) Synthesis of 1,3,5-trisubstituted pyrazoles developed by our group. b) General approach for the synthesis of 2-(pyrazol-3-yl)pyridines explored in this work. c) Structures prepared in this work.

\section{Results and discussion}

Synthesis of 2-(pyrazol-3-yl)pyridines by the cascade reaction We initiated our study by focusing on the reaction between $\mathrm{N}$ tosylhydrazones 1 and 2-alkynylpyridines 2 (Scheme 2). ${ }^{\S}$ We had previously demonstrated that in order to drive the 1,5rearrangement to the nitrogen atom, and obtain the desired 1,3,5-trisubstituted pyrazoles, the starting $N$-tosylhydrazone must feature a $\pi$-electrondonating substitutent $(X)$ at the $\alpha$ position. Thus, we concentrated our study towards this particular type of $\mathrm{N}$-tosylhydrazones.

We took as starting point the reaction conditions that had been previously developed for the synthesis of 1,3,5-trisubstituted pyrazoles: ${ }^{15}$ treatment of an equimolar mixture of tosylhydrazone 1 and terminal alkyne 2 in 1,4-dioxane at $110^{\circ} \mathrm{C}$, and in the presence of an excess of $\mathrm{K}_{2} \mathrm{CO}_{3}$ (Scheme 2). After some experimentation it was discovered that in these cases acetonitrile was the best solvent to achieve the transformations. Additionally, in some instances it was recommended slow syringe pump addition of a solution of the $\mathrm{N}$-tosylhydrazone to the reaction mixture. These conditions were applied to a variety of $\mathrm{N}$-tosylhydrazones $\mathbf{1}$ and 2alkynylpyridines $\mathbf{2}$ to provide a set of structurally diverse 2(pyrazol-3-yl)pyridines $\mathbf{3}$ (Scheme 2, Table 1). Noteworthy, the structural variety of pyrazolylpyridines $\mathbf{3}$ that can be accessed is remarkable. Variations in the structure of the $\mathrm{N}$-tosylhydrazone 1 enable to introduce different substitution in the pyrazole ring. On one side, aryl and alkyl groups can be placed at position 5 of the pyrazole. Moreover, it is particularly interesting the substitution at $\mathrm{N} 1$ in the pyrazole. Benzyl (3a, 3b) and methoxymethyl (3c) can be introduced by employing the $N$ tosylhydrazones $\mathbf{1 a}$ and $\mathbf{1} \mathbf{b}$ respectively. Additionally, the use of the $N$-tosylhydrazone 1 c derived from $\alpha$ methoxycyclohexanone provides the interesting condensed sytems 3d-3f, with expansion of the saturated ring. The use of $N$-tosylhydrazones $\mathbf{1 d}$ and $1 \mathbf{e}$ derived from $\alpha$-( $N$-azole)substituted ketones provided new pyrazolylpyridines which feature an additional heterocycle. Thus, derivatives having three different heterocycles are assembled in a very simple manner. Particularly appealing are the derivatives of $\mathrm{N}$ tosylhydrazone $\mathbf{1 d}$, that carries another pyrazole ring, as the adducts obtained $(\mathbf{3 g}, \mathbf{3 h})$ are a new class of potential $\mathrm{N}, \mathrm{N}, \mathrm{N}-$ tridentated ligands.

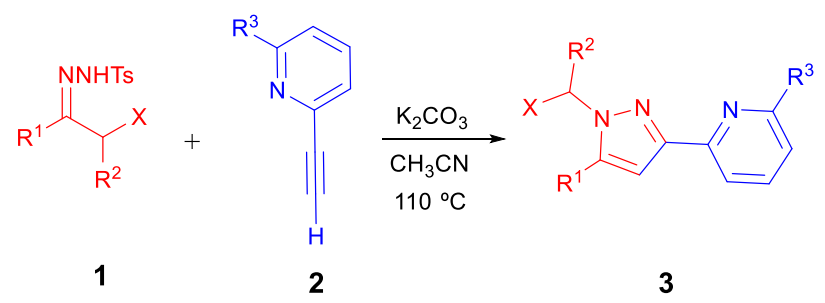

Scheme 2. Synthesis of 2-(pyrazol-3-yl)pyridines $\mathbf{3}$.

In our previous work, we had demonstrated that when $\mathrm{N}$ tosylhydrazones featuring a stereogenic center at the $\alpha$ position are used, the 1,3-dipolar cycloaddition/1,5-sigmatropic rearrangement sequence takes place with retention of configuration on the migrating group, ${ }^{16}$ therefore, enantiomerically pure pyrazoles featuring a stereogenic group attached at $\mathrm{N} 1$ are obtained. This reaction was applied for the preparation of chiral enantiomerically pure pyrazolopyridines featuring a stereogenic center on the nitrogen of the pyrazole. To this purpose, the tosylhydrazones $\mathbf{1 f}$, derived from L-proline, 
and $\mathbf{1 g}$ obtained from $L$-leucine were used leading to the chiral adducts $\mathbf{3 k}, \mathbf{3} \mathbf{l}$, and $\mathbf{3} \mathbf{m}$ respectively. Finally, in many reactions with $N$-tosylhydrazones, the processes can be conducted by generating the hydrazone in situ from the corresponding carbonyl and $N$-tosylhydrazide. We explored this approach for the synthesis of adduct $\mathbf{3 j}$. Indeed, the product $\mathbf{3} \mathbf{j}$, featuring a pyrazole, a triazole and a pyridine ring was obtained, although in poorer yield than the typical reactions starting from the isolated $N$-tosylhydrazone.

Table 1. 2-(Pyrazol-3-yl)pyridines 3 synthesized by the method depicted in scheme 2.a)

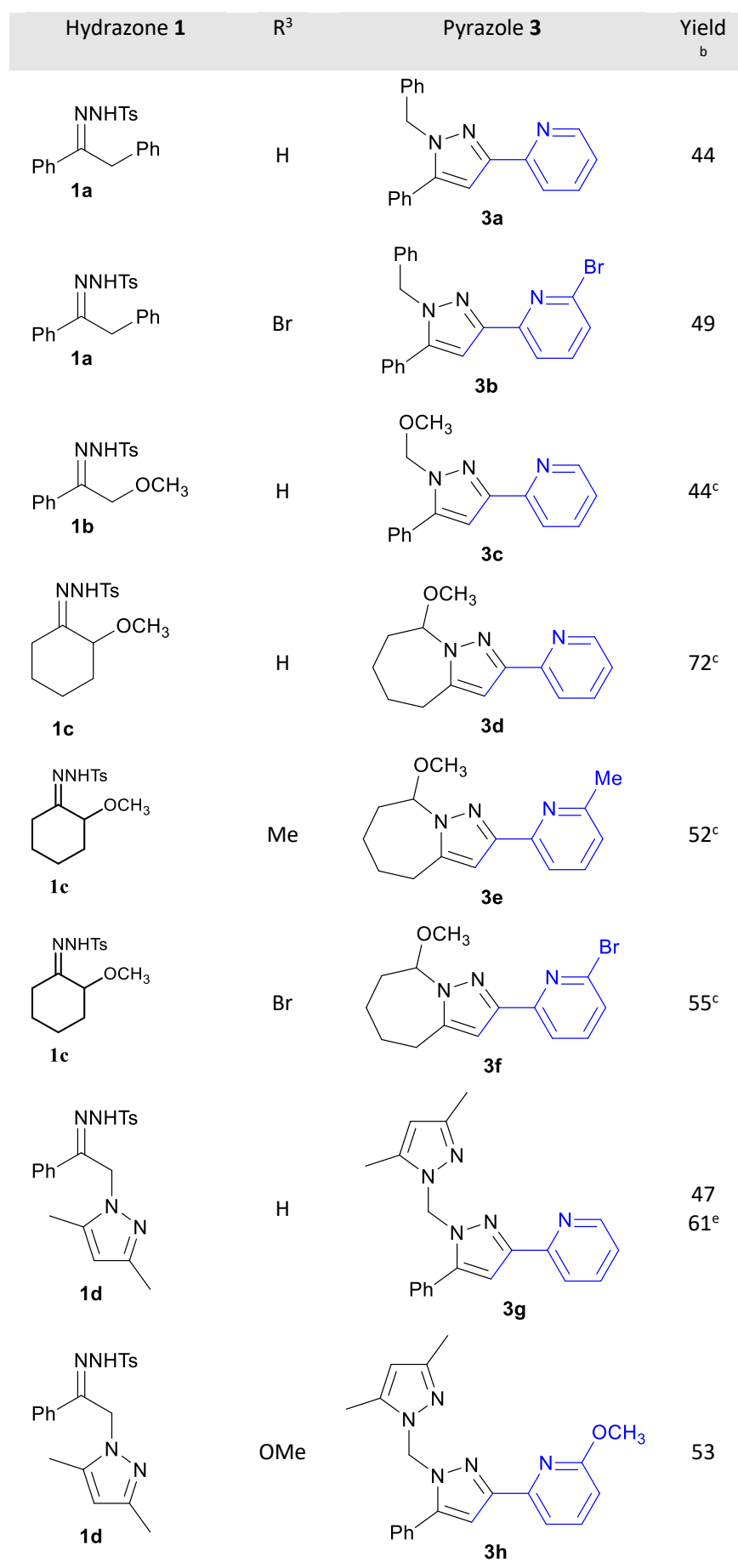

$\mathrm{H}$

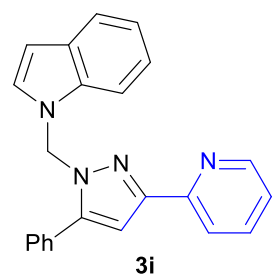

$47^{c}$

1e<smiles>NN[14CH2][14CH2]C(=O)c1ccccc1</smiles>

H

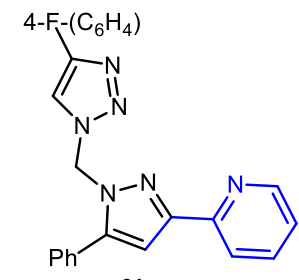

3j

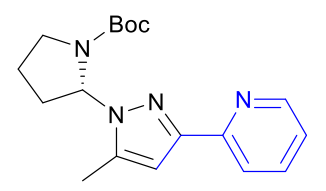

3k<smiles>CC(=N[PH3])[C@@H]1CCCN1C(=O)OC(=O)c1ccccc1</smiles>

$\mathrm{C} \equiv \mathrm{C}$<smiles>C#Cc1cccc(-c2cc(C)n([C@@H]3CCCN3C(=O)OC(C)(C)C)n2)n1</smiles>

31

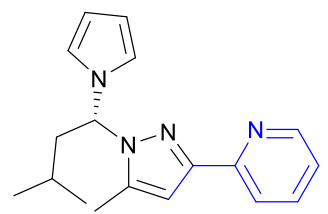

$3 \mathrm{~m}$

a) Reaction conditions: 1 (0.2-0.3 mmol, 1.2 equiv), 2 (1 equiv), $\mathrm{K}_{2} \mathrm{CO}_{3}$ (2.4 equiv), $\mathrm{CH}_{3} \mathrm{CN}, 110^{\circ} \mathrm{C}$. b) Isolated yields after column chromatography. ${ }^{\mathrm{c}}$ Carried out with slow addition of the tosylhydrazone 1. d) Prepared in a one-pot process from the corresponding ketone, $\mathrm{N}$-tosylhydrazide and the 2-ethynylpyridine. e) Reaction at $1 \mathrm{mmol}$ scale.

Regarding the structure of the alkynylpyridine, the method tolerates a variety of substitutions at $\mathrm{C} 6$, including not only alkyl, but also a bromine (3b) and an alkoxyde (3h), which could be easily derivatized. Moreover, under controlled conditions, the reaction with 2,6-diethynylpyridine proceeded at only one of the two triple bonds leading to the derivative $\mathbf{3}$ l that features the terminal triple bond that could be subjected to further modifications.

We had demonstrated that the presence of a $\pi$ electrondonating group at the $\alpha$-position of the $\mathrm{N}$ tosylhydrazone is essential to drive the 1,5-rearrangement reaction to $\mathrm{N} 1$. In the absence of the electrondonating group, the 1,5-sigmatropic rearrangement takes place to C4 with preferent migration of the aryl group. To illustrate that this behaviour was also retained in the reactions with alkynylpyridines, the reaction with tosylhydrazone $\mathbf{1 h}$, derived from a tetralone was examined. As expected, the pyrazolopyridines 4, featuring the free $\mathrm{NH}$ were obtained (Scheme 3). Noteworthy, these are also very appealing 
structures for coordination chemistry and catalysis, ${ }^{17}$ and additionally could be easily derivatized at the $\mathrm{NH}$ position to increase the molecular complexity.

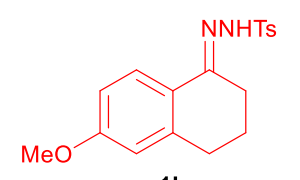

$1 \mathrm{~h}$

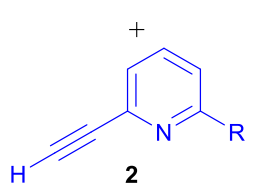

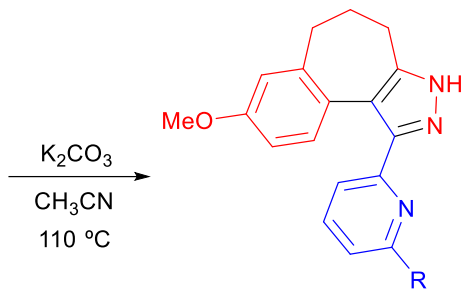

4a, $\mathrm{R}=\mathrm{H}, 50 \%$ 4b, $\mathrm{R}=\mathrm{Me}, 71 \%$
Scheme 3. Synthesis of NH-free 2-(pyrazol-3-yl)pyridines 4.

Then, we decided to explore the cascade process with 2,6diethynylpyridine $\mathbf{2} \mathbf{e}$ oriented to the synthesis of pincer NNNtridentate ligands upon a double cycloaddition/rearrangement sequence. The reactions were conducted under the same conditions but employing an excess of the $N$-tosylhydrazone. Delightfully, the adducts 5, featuring the 2,6bis(pyrazolyl)pyridine moiety were obtained (Scheme 4).

The 2,6-bis(pyrazolyl)pyridines $\mathbf{5}$ are obtained with only moderate yields. Nevertheless, it must be taken into account that the same cascade reaction must take place twice on the same adduct. Moreover, it is remarkable the high complexity that is achieved under very simple experimental conditions and from readily available precursors. Therefore, it is indeed a synthetically useful transformation. It should be highlighted in particular compound $\mathbf{5 b}$ that features the arrangement of five nitrogen atoms in a proper position to behave as a NNNNNpentadentate ligand. The compound $\mathbf{5 c}$, that has been prepared from $L$-proline, is also noteworthy, as it is an example of a novel C2 symmetric enantiomerically pure tridentate ligand.

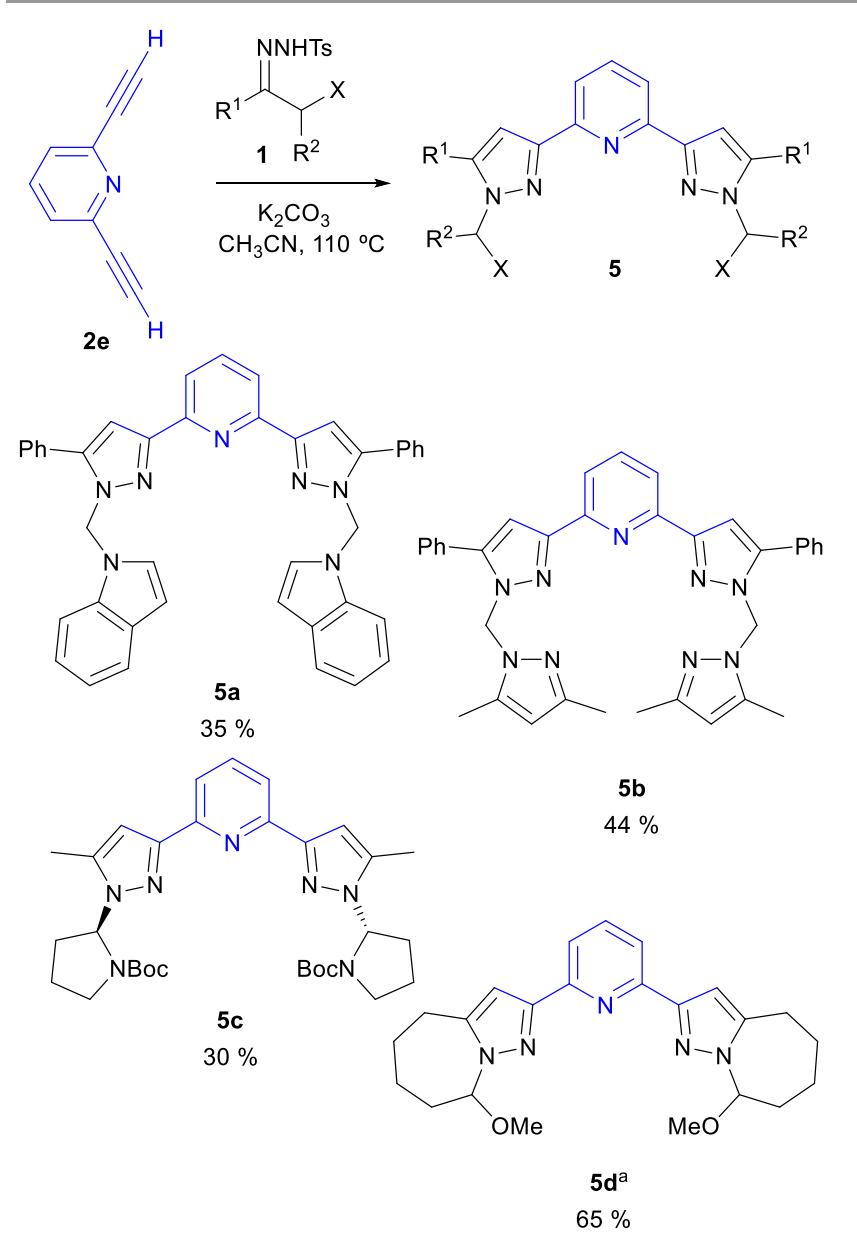

Scheme 4. Synthesis of 2,6-bis(pyrazolyl)pyridines 5 by reaction of $2 \mathrm{e}$ with $\mathrm{N}$ tosylhydrazones 1 . a) Slow addition of the $\mathrm{N}$-tosylhydrazone $\mathbf{1}$.

\section{Three-component reactions}

$\alpha$-Halo- $N$-tosylhydrazones are valuable intermediates for multicomponent reactions. Upon treatment with a base they undergo dehydrohalogenation to give $\alpha, \beta$-unsaturated azoalkenes, that may suffer conjugate addition of a proper nucleophile to give a substituted $N$-tosylhydrazone salt, ${ }^{18}$ that in turn might experiment thermal decomposition to generate a diazo compound. Recently Wang et al took advantage of this strategy to develop novel three-component cross-couplings using $\alpha$-bromo- $N$-tosylhydrazones and C-nucleophiles (Scheme 5 , a). ${ }^{19}$ We envisioned that the base promoted generation of the azoalkene $\mathbf{C}$ in the presence of a $\mathrm{NH}$-azole might lead to tosylhydrazone salt $\mathbf{D}$ upon nucleophilic attack of the azole anion to the azoalkene, which is an ideal substrate for our pyrazole synthesis. Therefore, we set out to develop a new three-component pyrazole synthesis combining the formation of a functionalized diazo compound with the 1,3-dipolar cycloaddition/1,5-rearrangement process. Thus, the formation of the pyrazole through the three-component reaction should involve: 1) formation of azoalkene $\mathbf{C}$ by base promoted elimination on the $\alpha$-bromo- $N$-tosylhydrazone; 2 ) nucleophilic attack of the azolyl anion to produce the $N$-tosylhydrazone salt D; iii) generation of diazo compound $\mathbf{E}$ by thermal 
decomposition of $\mathbf{D}$; iv) 1,3-dipolar cycloaddition to give $3 \mathrm{H}$ pyrazole F; v) 1,5-sigmatropic rearrangement to produce the final adduct (Scheme 5, b)

a)

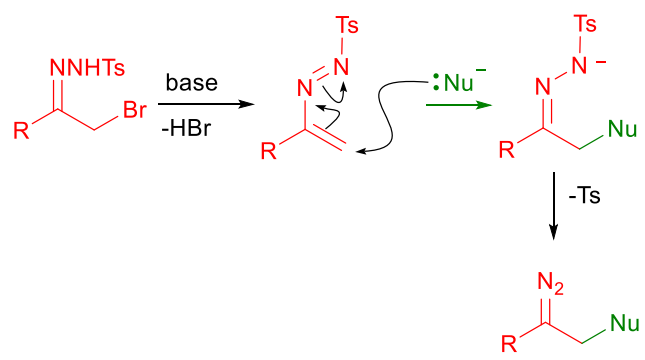
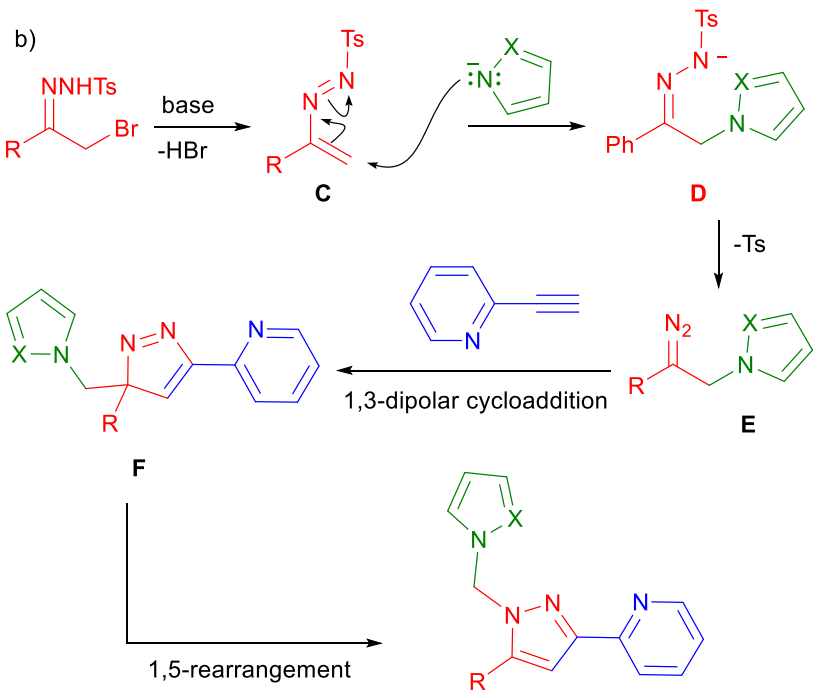

Scheme 5. a) Generation of substituted diazo compounds from $\alpha$-bromo- $N$ tosylhydrazones. b) Our proposal for a three-component synthesis of pyrazolopyridines.

In an initial experiment we mixed the $N$-tosylhydrazone 6 a, derived from 2'-bromoacetophenone, 2-ethynylpyridine $\mathbf{2 a}$ and 3,5-dimethylpyrazole 7 in the presence of an excess of $\mathrm{K}_{2} \mathrm{CO}_{3}$. The adduct $\mathbf{3 g}$ was isolated although in low yield. After some optimization work, it was determined that best results were obtained by employing a 2: 2: 1, hydrazone 6a: alkyne 2a: pyrazole 7 molar ratio, in the presence of 5 equiv of $\mathrm{K}_{2} \mathrm{CO}_{3}$, leading to compound $\mathbf{3 g}$ in high yield (Scheme 6).
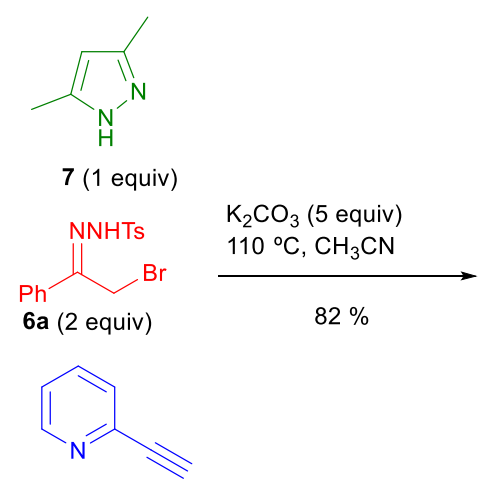

2a (2 equiv)

Scheme 6. . Three-component synthesis of pyrazolopyridine 3g. Preliminary results.
To illustrate the versatility of this new three-component methodology a collection of pyrazolopyridines $\mathbf{3}$ was prepared (Scheme 7).
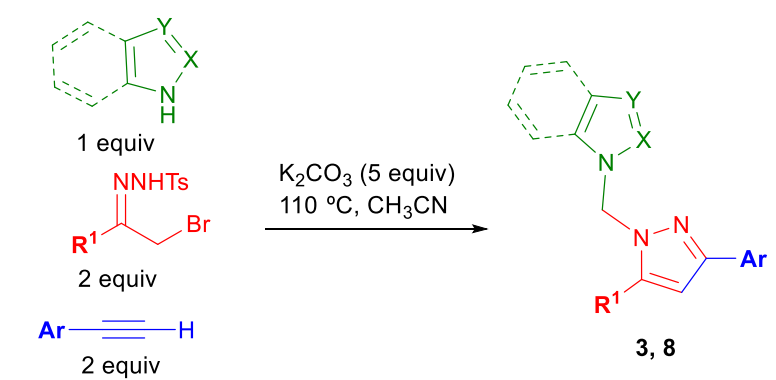

3, 8
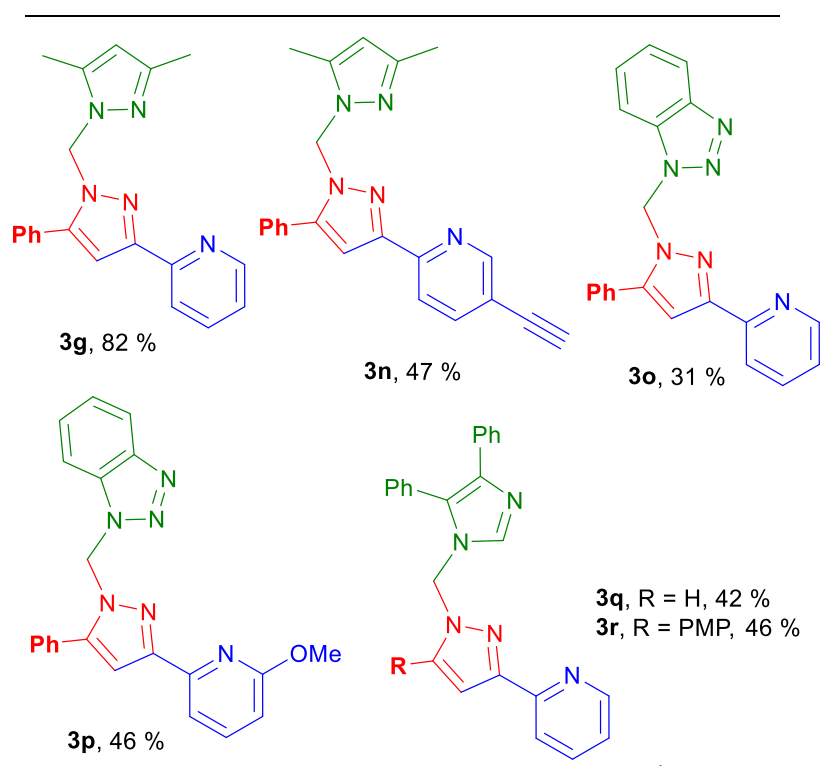

$3 q, \mathrm{R}=\mathrm{H}, 42 \%$

$3 r, R=P M P, 46 \%$

$3 p, 46 \%$
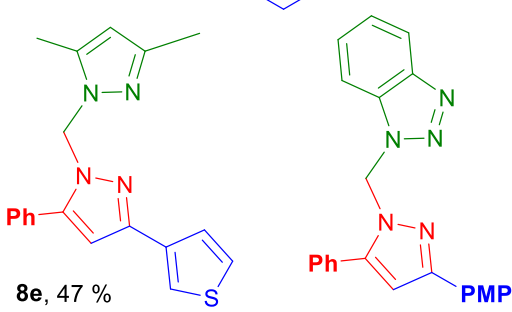

$8 f, 52 \%$
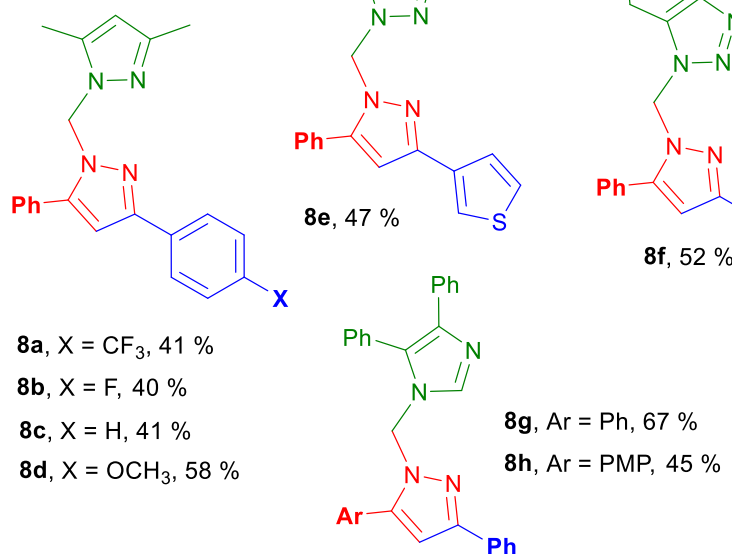

Scheme 7. Three-component synthesis of structurally diverse trisubstituted pyrazoles 3 and 8 .

Several different azoles can be introduced as nucleophiles (green color) by means of this strategy, including pyrazoles, benzotriazole and imidazole. Importantly, the reaction is not restricted to the employment of 2-ethynylpyridines. Indeed, other terminal alkynes were examined in the multi-components process successfully, leading to new trisubstituted pyrazoles $\mathbf{8}$ featuring an additional aryl or heteroaryl substituent. This 
three-component reaction is remarkable, as it yields the important pyrazole heterocycles, with three points of diversity and from readily available reactants. ${ }^{20}$ Moreover, these are also the first examples of the in situ generation and further reaction of $\alpha$-( $N$-azole)- $N$-tosylhydrazones, versatile reagents in the synthesis of polyheterocycles. ${ }^{21,22}$

\section{One-pot/four-component reaction}

It is well known that many of the reactions that involve $\mathrm{N}$ tosylhydrazones can be carried out in a one pot fashion, starting from the corresponding ketone and tosylhydrazide, by generating the $\mathrm{N}$-tosylhydrazone in situ. ${ }^{23}$ To push the applicability of the multicomponent reaction even further, we decided to examine this strategy, and combine the one pot generation of the $\alpha$-bromo- $N$-tosylhydrazone 6 with the threecomponent cascade synthesis of pyrazoles.
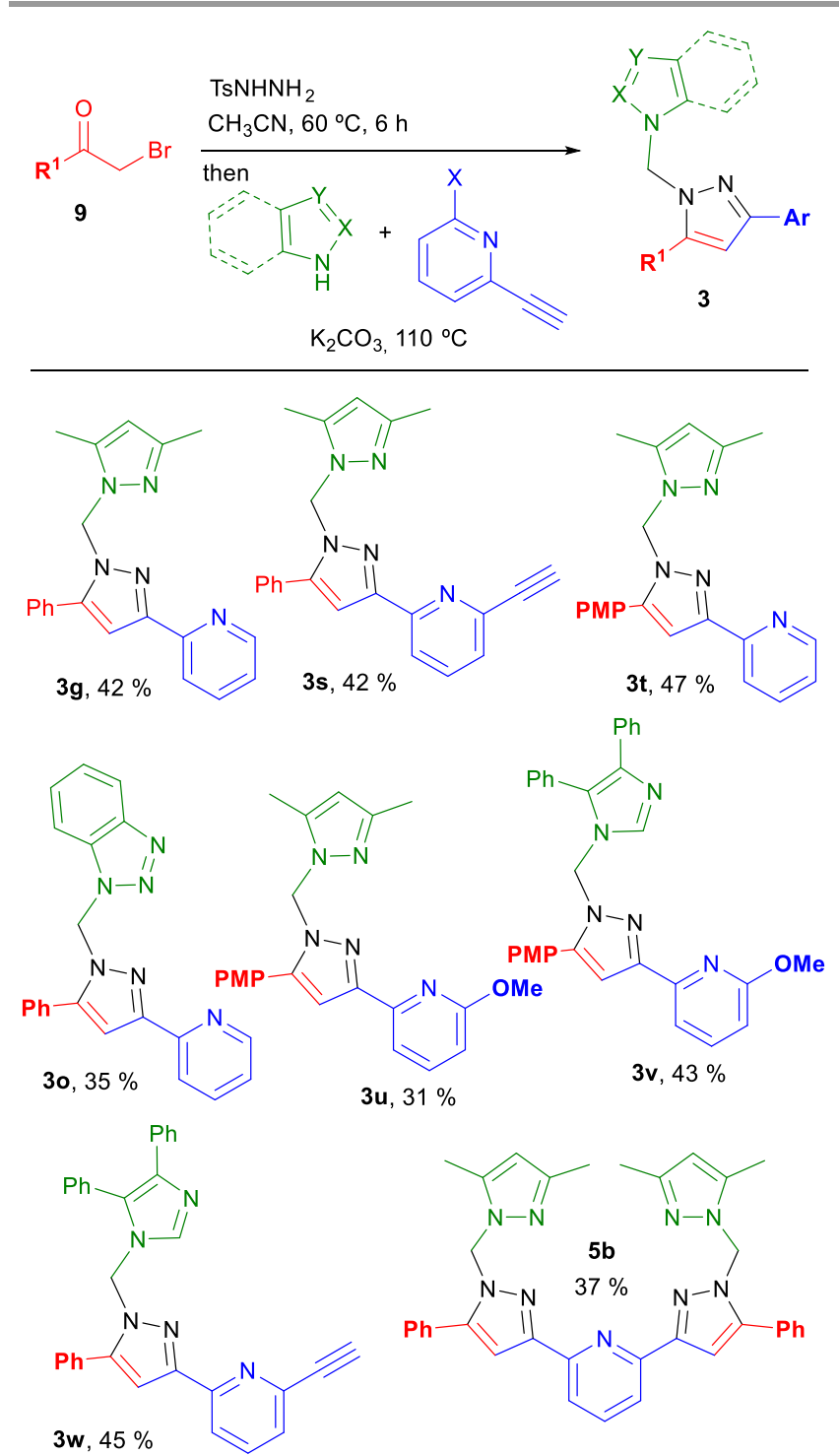

Scheme 8. One pot/four-component synthesis of 2-(pyrazol-3-yl)pyridines 3 directly from $\alpha$-bromoketones 9 .

The one pot/four-component sequence could be accomplished by treating the $\alpha$-bromoketone 9 with tosylhydrazide in $\mathrm{CH}_{3} \mathrm{CN}$ at $60^{\circ} \mathrm{C}$ for $6 \mathrm{~h}$, followed by the addition of the alkyne, the $\mathrm{NH}$ azole and $\mathrm{K}_{2} \mathrm{CO}_{3}$. Using this procedure, the 2-(pyrazol-3$\mathrm{yl}$ )pyridines $\mathbf{3}$ were obtained with moderate yields (Scheme 8). Nevertheless, it must be noted that the highly complex trisubstituted pyrazoles are assembled in one single operational step directly from commercially available materials. Remarkably, the one pot/four-component strategy was also appropriate for the 2,6-bis(pyrazolyl)pyridine $\mathbf{5 b}$.

Finally, we have shown that under the proper experimental conditions, the reactions with 2,6-diethynylpyridine can be controlled to give the 2-(pyrazol-3-yl)pyridines $\mathbf{3}$ leaving one of the triple bonds untouched (3I, 3s, $\mathbf{3} \mathbf{w})$, and susceptible of a further derivatization. To illustrate the usefulness of the selective transformation, compound $3 \mathbf{s}$ was subjected to a $\mathrm{Cu}$ catalyzed azide-alkyne cycloaddition (Scheme 9). ${ }^{24}$ In this manner, the reaction of $3 \mathrm{~s}$ with sodium azide and bromoketone 6a led to the new adduct 10, featuring four different heterocycles, and interestingly, with the proper arrangement of a tetradentate NNNN ligand (Scheme 9). This example shows the potential of this approach for the generation of molecular diversity around the 2-(pyrazol-3-yl)pyridine moiety, as compound $\mathbf{1 0}$ has been synthesized in only two steps from commercially available starting materials.

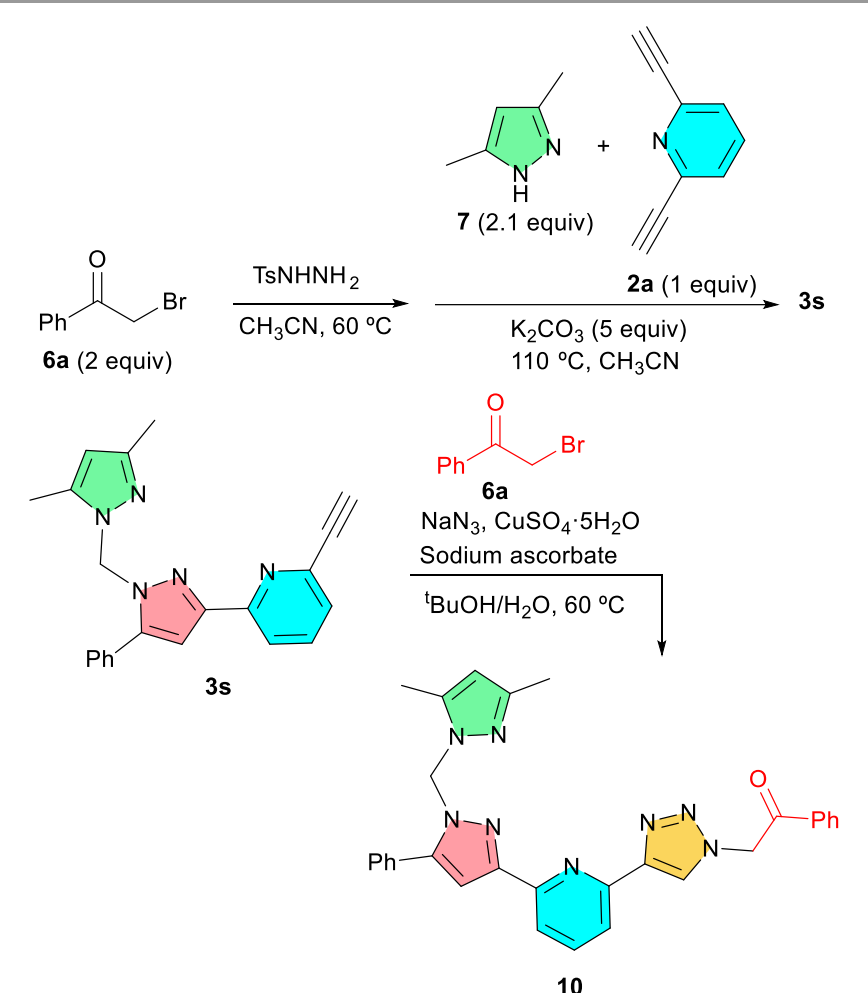

Scheme $\mathbf{9}$. Two steps synthesis of polyheterocyclic system $\mathbf{1 0}$ by the cascade pyrazole formation/CuAAC sequence.

\section{Experimental section}

Details of experimental conditions, characterization data and copies of ${ }^{1} \mathrm{H}$ and ${ }^{13} \mathrm{C}$ NMR spectra for all isolated compounds are included in the Supplementary Information. 
General procedure for the synthesis of 2-(pyrazol-3yl)pyridines from $\mathbf{N}$-tosylhydrazones 1 and 2-alkynylpyridines 2.

A reaction tube was charged with $N$-tosylhydrazone $1(0.24$ mmol), 2-ethynylpyridine $2(0.2 \mathrm{mmol})$ and $\mathrm{K}_{2} \mathrm{CO}_{3}(0.4 \mathrm{mmol}, 55$ $\mathrm{mg}$ ) and $2 \mathrm{ml}$ of $\mathrm{CH}_{3} \mathrm{CN}$ and the mixture was stirred at $110^{\circ} \mathrm{C}$ for $16 \mathrm{~h}$ under nitrogen atmosphere. Then, the reaction was allowed to reach room temperature and was treated with $10 \mathrm{~mL}$ of $\mathrm{CH}_{2} \mathrm{Cl}_{2}$ and $10 \mathrm{~mL}$ of $\mathrm{NaHCO}_{3}$ saturated aqueous solution. The layers were separated and the aqueous phase was extracted with $\mathrm{CH}_{2} \mathrm{Cl}_{2}(2 \times 5 \mathrm{~mL})$. The organic layers were combined, washed with brine $(5 \mathrm{~mL})$, dried over $\mathrm{Na}_{2} \mathrm{SO}_{4}$, filtered, and the solvent was removed under reduced pressure. The resulting oily residue was purified by flash chromatography in silica gel to afford the 2-(pyrazol-3-yl)pyridine.

General Procedure with slow addition of the $\mathrm{N}$ Tosylhydrazone.

A reaction tube was charged with 2-ethynylpyridine 2 (0.2 mmol) and $\mathrm{K}_{2} \mathrm{CO}_{3}(0.4 \mathrm{mmol}, 55 \mathrm{mg})$ and $1 \mathrm{ml}$ of $\mathrm{CH}_{3} \mathrm{CN}$ under nitrogen atmosphere and the solution was heated to $100{ }^{\circ} \mathrm{C}$. Then, a solution of the $N$-tosylhydrazone $1(0.3 \mathrm{mmol})$ in $1 \mathrm{ml}$ of $\mathrm{CH}_{3} \mathrm{CN}$ was slowly added with a syringe pump over a period of $2 \mathrm{~h}$. The mixture was stirred for $16 \mathrm{~h}$ at $100^{\circ} \mathrm{C}$. Then, the workup of the reaction is identical to that described above.

General procedure for the synthesis of 2,6bis(pyrazolyl)pyridines 5 by reaction of $\boldsymbol{N}$-tosylhydrazones 1 with 2,6-ethynylpyridine

The procedure is identical to that described above for 2(pyrazol-3-yl)pyridines but employing $0.2 \mathrm{mmol}$ of 2,6diethynylpyridine $2 \mathrm{e}, 0.8 \mathrm{mmol}$ of $\mathrm{N}$-tosylhydrazone and 0.8 $\mathrm{mmol}\left(110 \mathrm{mg}\right.$ ) of $\mathrm{K}_{2} \mathrm{CO}_{3}$.

General procedure for the three-component synthesis of 2(pyrazol-3-yl)pyridines from $\alpha$-bromo- $\mathrm{N}$-tosylhydrazones 6, 2 alkynylpyridines $\mathbf{2}$ and $\mathbf{N H}$-azoles.

A reaction tube was charged with the $\alpha$-bromo- $N$ tosylhydrazone $6(0.2 \mathrm{mmol})$, 2-ethynylpyridine $2(0.2 \mathrm{mmol})$, the $\mathrm{NH}$-azole $(0.1 \mathrm{mmol}), \mathrm{K}_{2} \mathrm{CO} 3(0.5 \mathrm{mmol}, 70 \mathrm{mg})$ and $3 \mathrm{ml}$ of $\mathrm{CH} 3 \mathrm{CN}$, and the mixture was stirred at $110^{\circ} \mathrm{C}$ for $16 \mathrm{~h}$ under nitrogen atmosphere. Then, the workup of the reaction is identical to that described above.

General procedure for the one pot/four-component synthesis of 2-(pyrazol-3-yl)pyridines from $\alpha$-bromoketones, $N$ tosylhydrazide, 2-alkynylpyridines and $\mathrm{NH}$-azoles.

A reaction tube was charged with the $\alpha$-bromoketone $(0.2$ $\mathrm{mmol})$, the $\mathrm{N}$-tosylhydrazide $(0.22 \mathrm{mmol})$ and $\mathrm{CH}_{3} \mathrm{CN}(1.5 \mathrm{ml})$ were. After $2-12 \mathrm{~h}$ at $60^{\circ} \mathrm{C}$, the 2-ethynylpyridine $(0.2 \mathrm{mmol})$, the $\mathrm{NH}$-azole $(0.1 \mathrm{mmol}), \mathrm{K}_{2} \mathrm{CO}_{3}(0.5 \mathrm{mmol}, 70 \mathrm{mg})$ and $2.5 \mathrm{ml}$ of $\mathrm{CH}_{3} \mathrm{CN}$ were added to the mixture and it was stirred at $110^{\circ} \mathrm{C}$ for $16 \mathrm{~h}$ under nitrogen atmosphere. Then, the workup of the reaction is identical to that described above.

\section{Conclusion}

As summary, in this work we have reported the application of the synthesis of pyrazoles by cascade reaction between $N$ - tosylhydrazones and alkynes to the preparation of structurally diverse 2-(pyrazol-3-yl)pyridines, interesting structures for their potential applications as NN bidentate ligands as well as their possible biological activity. Moreover, the application of the methodology to 2,6-diethynylpyridine led to the obtention of new 2,6-bis(pyrazolyl)pyridines. This method led to the preparation of new potential NNN-tridentate ligands and also unprecedented NNNNN-pentadentate ligands.

We have also developed new three-component and fourcomponent procedures for the synthesis of trisubstituted pyrazoles from $\alpha$-bromo- $N$-tosylhydrazones or $\alpha$ bromoketones, $\mathrm{NH}$-azoles and terminal alkynes. These methods allow for the assembly of various heterocyclic systems along with the construction of the trisubstituted pyrazoles. The variety of structures synthesized, (40 different adducts) clearly proves the versatility and usefulness of this multicomponent approach for the generation of molecular diversity.

\section{Conflicts of interest}

"There are no conflicts to declare".

\section{Acknowledgements}

Financial support of this work by Ministerio de Economía y Competitividad (MINECO) of Spain: Grant CTQ2016-76794-P (AEI/FEDER, UE) and Consejería de Empleo, Industria y Turismo del Principado de Asturias (Spain): (grant IDI/2018/000231). A Clarín postdoctoral fellowship (Principado de Asturias, Spain) to A. J. and a FICYT (Principado de Asturias, Spain) predoctoral fellowship to R. B. are gratefully acknowledged.

\section{Notes and references}

$\S$ See supporting information for synthetic details.

1 (a) J. Elguero, A. M. S. Silva, A. C. Tomé in Modern Heterocyclic Chemistry, Vol. 2 (Eds. J. Alvarez-Builla, J. J. Vaquero, J.

Barluenga) Wiley-VCH, Weinheim, 2011, pp. 635-725. (b) S. Fustero, M. Sánchez-Roselló, P. Barrio and A. Simón-Fuentes, Chem. Rev., 2011, 111, 6984-7034.

2 (a) G. Küçükgüzel and S. ŞenkardeŞ, Eur. J. Med. Chem., 2015, 97, 786-815. (b) J. V. Faria, P. F. Vegi, A. G. C. Miguita, M. S. dos Santos, N. Boechat and A. M. R. Bernardino, Bioorganic Med. Chem., 2017, 25, 5891-5903. (c) A. Ansari, A. Ali, M. Asif and Shamsuzzaman, New J. Chem., 2016, 41, 16-41. (d) K. Karrouchi, S. Radi, Y. Ramli, J. Taoufik, Y. N. Mabkhot, F. A. AlAizari and M. Ansar, Synthesis and pharmacological activities of Pyrazole derivatives: A review, 2018, vol. 23.

3 J. Pérez and L. Riera, Eur. J. Inorg. Chem., 2009, 2009, 49134925.

4 M. Viciano-Chumillas, S. Tanase, L. J. de Jongh and J. Reedijk, Eur. J. Inorg. Chem., 2010, 2010, 3403-3418.

5 I. Dutta, S. Yadav, A. Sarbajna, S. De, M. Hölscher, W. Leitner and J. K. Bera, J. Am. Chem. Soc., 2018, 140, 8662-8666.

6 (a) E. Cavero, S. Uriel, P. Romero, J. L. Serrano and R. Giménez, 
J. Am. Chem. Soc., 2007, 129, 11608-11618. (b) E. Beltrán, E. Cavero, J. Barberá, J. L. Serrano, A. Elduque and R. Giménez, Chem. - A Eur. J., 2009, 15, 9017-9023. (c) S. Moyano, J. L. Serrano, A. Elduque and R. Giménez, Soft Matter, 2012, 8, 6799-6806.

7 (a) J. Salinas Uber, Y. Vogels, D. van den Helder, I. Mutikainen, U. Turpeinen, W. T. Fu, O. Roubeau, P. Gamez and J. Reedijk, Eur. J. Inorg. Chem., 2007, 2007, 4197-4206. (b) M. J. Moure, R. SanMartin and E. Domínguez, Adv. Synth. Catal., 2014, 356, 2070-2080. (c) M. N. Magubane, G. S. Nyamato, S. O. Ojwach and O. Q. Munro, RSC Adv., 2016, 6, 65205-65221.

8 (a) V. A. Krylova, P. I. Djurovich, J. W. Aronson, R. Haiges, M. T. Whited and M. E. Thompson, Organometallics, 2012, 31, 79837993. (b) J. P. Zhang, Y. Wang, J. B. Ma, L. Jin, F. T. Liu and F. Q. Bai, RSC Adv., 2018, 8, 19437-19448.

9 (a) M. Arroyo, P. Gómez-Iglesias, N. Antón, R. García-Rodríguez, E. C. B. A. Alegria, A. J. L. Pombeiro, D. Miguel and F. Villafañe, Dalt. Trans., 2014, 43, 4009-4020. (b) W. Cullen, M. C. Misuraca, C. A. Hunter, N. H. Williams and M. D. Ward, Nat. Chem., 2016, 8, 231-236. (c) J. S. Train, A. B. Wragg, A. J. Auty, A. J. Metherell, D. Chekulaev, C. G. P. Taylor, S. P. Argent, J. A. Weinstein and M. D. Ward, Inorg. Chem., 2019, 58, 2386-2396.

10 (a) J. S. Sawyer, D. W. Beight, K. S. Britt, B. D. Anderson, R. M. Campbell, T. Goodson, D. K. Herron, H. Y. Li, W. T. McMillen, N. Mort, S. Parsons, E. C. R. Smith, J. R. Wagner, L. Yan, F. Zhang and J. M. Yingling, Bioorganic Med. Chem. Lett., 2004, 14, 35813584. (b) H. Y. Li, W. T. McMillen, C. R. Heap, D. J. McCann, L. Yan, R. M. Campbell, S. R. Mundla, C. H. R. King, E. A. Dierks, B. D. Anderson, K. S. Britt, K. L. Huss, M. D. Voss, Y. Wang, D. K. Clawson, J. M. Yingling and J. S. Sawyer, J. Med. Chem., 2008, 51, 2302-2306. (c) D. K. Kim, Y. I. Lee, Y. W. Lee, P. M. Dewang, Y. Y. Sheen, Y. W. Kim, H. J. Park, J. Yoo, H. S. Lee and Y. K. Kim, Bioorganic Med. Chem., 2010, 18, 4459-4467. (d) R. Ciayadi, M. Potdar, K. L. Walton, C. A. Harrison, G. F. Kelso, S. J. Harris and M. T. W. Hearn, Bioorganic Med. Chem. Lett., 2011, 21, 56425645. (e) J. Kim, D. Lee, C. Park, W. So, M. Jo, T. Ok, J. Kwon, S. Kong, S. Jo, Y. Kim, J. Choi, H. C. Kim, Y. Ko, I. Choi, Y. Park, J. Yoon, M. K. Ju, J. Kim, S.-J. Han, T.-H. Kim, J. Cechetto, J. Nam, P. Sommer, M. Liuzzi, J. Lee and Z. No, ACS Med. Chem. Lett., 2012, 3, 678-682. (f) T. Fukuda, R. Goto, T. Kiho, K. Ueda, S. Muramatsu, M. Hashimoto, A. Aki, K. Watanabe and N. Tanaka, Bioorganic Med. Chem. Lett., 2017, 27, 3716-3722.

11 (a) M. A. Halcrow, Coord. Chem. Rev., 2005, 249, 2880-2908. (b) M. A. Halcrow, New J. Chem., 2014, 38, 1868-1882.

12 (a) L. J. Kershaw Cook, R. Mohammed, G. Sherborne, T. D. Roberts, S. Alvarez and M. A. Halcrow, Coord. Chem. Rev., 2015, 289-290, 2-12. (b) A. A. Pavlov, D. Y. Aleshin, I. A. Nikovskiy, A. V. Polezhaev, N. N. Efimov, A. A. Korlyukov, V. V. Novikov and Y. V. Nelyubina, Eur. J. Inorg. Chem., 2019, 2019, 2819-2829. (c) M. Attwood and S. S. Turner, Coord. Chem. Rev., 2017, 353, 247-277.

13 I. K. Naik, R. Bodapati, R. Sarkar, N. Mondal and S. K. Das, ACS Omega, 2018, 3, 3022-3035.

14 (a) K. M. Arendt and A. G. Doyle, Angew. Chemie Int. Ed., 2015, 54, 9876-9880. (b) N. S. Labrum, C. Chen and K. G. Caulton, Chem. - A Eur. J., 2019, 25, 7935-7940.

15 (a) M. C. Pérez-Aguilar and C. Valdés, Angew. Chemie - Int. Ed.,
2013, 52, 7219-7223. (b) R. R. Merchant, D. M. Allwood, D. C. Blakemore and S. V. Ley, J. Org. Chem., 2014, 79, 8800-8811.

16 M. C. Pérez-Aguilar and C. Valdés, Angew. Chemie - Int. Ed., 2015, 54, 13729-13733.

17 (a) S. Kuwata and T. Ikariya, Chem. - A Eur. J., 2011, 17, 35423556. (b) K. Umehara, S. Kuwata and T. Ikariya, J. Am. Chem. Soc., 2013, 135, 6754-6757.

18 (a) C. E. Sacks and P. L. Fuchs, J. Am. Chem. Soc., 1975, 97, 7372-7374. (b) J. M. Hatcher and D. M. Coltart, J. Am. Chem. Soc., 2010, 132, 4546-4547.

19 (a) G. Wu, Y. Deng, H. Luo, J. Zhou, T. Li, Y. Zhang and J. Wang, Chem. Commun., 2016, 52, 5266-5268. (b) G. Wu, Y. Deng, H. Luo, T. Li, Y. Zhang and J. Wang, Asian J. Org. Chem., 2016, 5, 874-877.

20 (a) S. Maddila, S. B. Jonnalagadda, K. K. Gangu and S. N. Maddila, Curr. Org. Synth., 2017, 14, 634-653. (b) Preeti and K. N. Singh, Org. Biomol. Chem., 2018, 16, 9084-9116.

21 L. Florentino, F. Aznar and C. Valdés, Chem. - A Eur. J., 2013, 19, 10506-10510.

22 I. A. Ibarra, A. Islas-Jácome and E. González-Zamora, Org. Biomol. Chem., 2018, 16, 1402-1418.

23 (a) J. Barluenga, M. Tomás-Gamasa, P. Moriel, F. Aznar and C. Valdés, Chem. - A Eur. J., 2008, 14, 4792-4795. (b) J. Barluenga, M. Tomás-Gamasa, F. Aznar and C. Valdés, Nat. Chem., 2009, 1, 494-499.

24 F. Himo, T. Lovell, R. Hilgraf, V. V. Rostovtsev, L. Noodleman, K. B. Sharpless and V. V. Fokin, J. Am. Chem. Soc., 2005, 127, 210216.

This document is the Accepted M anuscript version of a Published Work that appeared in final form in Organic and Biomolecular Chemistry, after peer review and technical editing by the publisher. $T 0$ access the final edited and published work https://doi.org/10.1039/C9OB02691F 